\title{
Terra, Luta e Trans(formação) no Movimento Indígena de Roraima
}

\author{
João Francisco Kleba Lisboa \\ Universidade de Brasília - UnB \\ e-mail: jfklisboa@gmail.com
}

\begin{abstract}
Resumo
Neste artigo busca-se discutir a relação entre as lutas por demarcação de terras indígenas no estado de Roraima, extremo Norte do Brasil, que contou com a participação ativa de indígenas em lugares até então inéditos, e a construção das principais organizações indígenas de Roraima, assim como o recente investimento daqueles povos indígenas (sobretudo os Macuxi e Wapichana) na construção de espaços de educação específica e diferenciada e no ingresso nas universidades. A luta por direitos permanece após a demarcação da Terra Indígena Raposa Serra do Sol, e a educação formal entra na pauta das reivindicações do movimento indígena, assim como é por este utilizada para fortalecer e consolidar sua "agencialidade" e seu poder de mobilização.
\end{abstract}

Palavras-chave: movimento indígena; transformação; educação formal; raposa-serra do sol.

\begin{abstract}
This article aims to discuss the relationship between the struggles for demarcation of indigenous lands in the state of Roraima, extreme north of Brazil, with the active participation of Indians in previously unprecedented places, and the construction of the main indigenous organizations of Roraima, as well as the recent investment of these indigenous peoples (mainly the Macuxi and Wapichana) in the construction of spaces of specific and differentiated education and in the entrance in the universities. The struggle for rights remains after the demarcation of the Raposa Serra do Sol Indigenous Land, and formal education is part of the Indigenous movement's demands, as it is used to strengthen and consolidate its "agency" and its mobilization power.
\end{abstract}

Keywords: indigenous movement; transforming; formal education; raposa-serra do sol.

\section{Introdução}

Com este artigo, pretendo expor e debater uma parte importante da atual situação e da história recente do movimento indígena no estado de Roraima, extremo Norte do Brasil. Ao mesmo tempo, abordo brevemente a luta pela terra - especificamente a Terra Indígena Raposa Serra do Sol, cuja fase judicial do processo demarcatório encerrou-se apenas em 2013, com o julgamento dos embargos declaratórios (as famosas "condicionantes") pelo Supremo Tribunal Federal (STF) - e busco vinculá-la à construção tanto das organizações indígenas mais consolidadas naquele estado - o Conselho Indígena de Roraima (CIR) e a Organização dos Professores Indígenas de Roraima (OPIR) - quanto da busca por formação escolar e universitária. 
Tais espaços de educação formal, assim como as organizações indígenas, revelam-se locais de formação e consolidação do movimento indígena, além de motor de mobilização para o alcance de suas reivindicações e de transformações que vêm sendo operadas em seu cotidiano. Ao final do artigo, discuto brevemente o quanto a ideia de transformação indígena pode estar ligada a uma reposta que esses povos estão dando ao processo de invasão colonial (ligado, por sua vez, a uma noção de transformação histórica unilinear e pré-determinada) que se acometeu sobre eles. $O$ artigo apresenta parte dos resultados de minha pesquisa de doutorado em Antropologia pela UnB, sob orientação de Stephen G. Baines ${ }^{1}$.

\section{Terra Indígena Raposa Serra do Sol: mobilização e conquista}

A demarcação da Terra Indígena Raposa Serra do Sol (TIRSS) foi de fato uma conquista inestimável para as populações indígenas do estado de Roraima e um marco recente de reconhecimento dos direitos indígenas. Stephen Baines (2012a), aponta que a demarcação da TIRSS em área contínua contrasta com o modelo antes existente de demarcações "em ilhas"2, que havia sido aplicado em procedimentos anteriores à organização do movimento indígena de Roraima, ou seja, quando os indígenas do estado estavam fragilizados e sem meios eficazes de defesa de seus direitos. Mesmo com a homologação do longo e pedregoso processo demarcatório da TIRSS, assinada pelo presidente Lula em 2005 - que foi pessoalmente ao local, em ato que passou a integrar o calendário de datas comemorativas dessas comunidades - os indígenas continuariam cobrando das autoridades a "garantia e a proteção integral de suas terras e dos recursos naturais, onde arrozeiros invasores continuaram, até o início de 2009, a explorar indevidamente as terras e os rios" (BAINES, 2012b, p. 40). Apenas com a decisão final do STF, em março de 2009, é que os habitantes originários do lugar tiveram a garantia pelo Estado de seu usufruto

\footnotetext{
1 Trata-se de pesquisa de campo realizada no estado de Roraima entre os anos de 2014 e 2016, de forma intermitente, incluindo uma estadia de seis meses e outra de dois na cidade de Boa Vista e arredores, além de outras visitas mais curtas (de três a duas semanas) ao estado. Acompanhei de perto, por meio de observação participante, a vida dos estudantes indígenas na Universidade Federal de Roraima (UFRR) e também de outras instituições de ensino superior, além de indígenas já formados e lideranças comunitárias ou dirigentes de organizações indígenas. Disto resultou minha tese, defendida em 05 de maio de 2017, intitulada "Acadêmicos Indígenas em Roraima e a construção da interculturalidade indígena na universidade: entre a formação e a transformação".

${ }^{2}$ Segundo Baines (2012a) as demarcações em ilhas consistem em "demarcações de terras indígenas em pequenas áreas cercadas por fazendas na região da Serra da Lua, ao sul, e Amajari e Alto Alegre, ao oeste, onde a maioria das terras indígenas é de extensão reduzida para sustentar suas populações que estão em pleno crescimento. A demarcação fragmentada destas outras terras indígenas, região ocupada por fazendeiros antes da consolidação do movimento indígena em Roraima e consequente reivindicação dos seus direitos originários aos seus territórios, resultou em uma situação atual de frequentes conflitos entre fazendeiros e povos indígenas e falta de terras para suas populações indígenas em crescimento"(p. 44).
} 
exclusivo sobre a terra, uma porção de 1,7 milhão de hectares no nordeste de Roraima.

De acordo com Paulo Santilli, o surgimento do Conselho Indígena de Roraima (CIR) resultou de uma estratégia política encontrada pelos indígenas (em especial os Macuxi, Wapichana e Taurepang) para fazer frente às invasões de seu território, sendo que as dimensões da Terra Indígena Raposa Serra do Sol e o aprendizado com derrotas locais anteriores exigiram uma maior centralização de esforços, o que não havia sido possível nos outros episódios, como o da exígua Área Indígena Ouro, que conta com apenas uma aldeia de mesmo nome, e demais comunidades demarcadas "em ilhas", com áreas diminutas. Assim, a criação do CIR, a partir de sete Conselhos Regionais ${ }^{3}$ definidos nas Assembleias Anuais de Tuxauas, esteve diretamente ligada à luta pela demarcação da TIRSS, sendo que a história de ambos se confunde. Como diz Santilli: "a construção de uma organização política verticalizada responde, em muito, à construção de uma unidade territorial abrangente, que é a área Raposa-Serra do Sol" (SANTILLI 2001, p. 94).

Atualmente à frente do departamento jurídico do CIR, Joênia Wapichana é uma das mais destacadas advogadas indígenas em atuação no país. Por ocasião do julgamento da ação popular $3.388 / 2005^{4}$, que emperrava havia anos a conclusão da demarcação da TIRSS, Joênia aproveitou para acusar a morosidade do processo demarcatório e a violência sofrida pelos indígenas de Roraima, com 21 lideranças assassinadas em 30 anos. Sua sustentação oral perante a Suprema Corte contribuiu para o êxito do pleito para o movimento indígena, com uma defesa irrefutável dos direitos indígenas previstos na Constituição Federal e com a afirmação da necessidade da terra para os povos que lá vivem (WAPICHANA, 2009). Tive a sorte de encontrá-la algumas vezes em Roraima, sobretudo em sua sala em Boa Vista, uma vez que a agenda de Joênia Wapichana é disputada pela participação em inúmeros congressos e fóruns internacionais, onde se

\footnotetext{
${ }^{3}$ De acordo com Santilli, os Conselhos Regionais consistiam em "instâncias supra-aldeãs, descoladas das comunidades locais, integradas por representantes de áreas geográficas delimitadas em função da concentração de aldeias, mas sobretudo da influência dos missionários, articulados às lideranças indígenas locais Macuxi, Ingaricó, Taurepang, Wapixana e Yanomami; foram, assim, criados sete Conselhos nas seguintes regiões: Serras, Surumu, Amajari, Serra da Lua, Raposa, Taiano e Catrimani. Sua incumbência era gerir as relações externas às comunidades indígenas, tanto no plano das relações com a sociedade regional, como na formulação $e$ direcionamento dos projetos indigenistas, patrocinados por diferentes agências"(SANTILLI, 2001, p. 43).

${ }^{4}$ Trata-se de Ação Popular, de autoria do senador da República Augusto Affonso Botelho Neto, tendo por assistente o também senador Francisco Mozarildo de Melo Cavalcanti, ambos representantes do estado de Roraima. Na ação, eles questionavam os atos demarcatórios da TIRSS, alegando, entre outros vícios, a falta de oitiva de todos os envolvidos e a parcialidade do laudo antropológico. Reconhecendo a "a incomum relevância político-social desta causa", como escreveu o relator do processo, ministro Carlos Ayres Britto, o STF manteve a validade da demarcação. Porém impôs as famigeradas "19 condicionantes", que viriam a ser confirmadas e minuciosamente detalhadas no julgamento dos embargos declaratórios, em 23 de outubro de 2013.
} 
discutem de direitos indígenas a questões ambientais, isso quando não está percorrendo as Terras Indígenas do estado para dar cursos de formação de operadores do direito nas comunidades ou resolver questões jurídicas e burocráticas ligadas aos direitos coletivos dos povos indígenas.

A participação da advogada Joênia Batista de Carvalho, ou Dra. Joênia Wapichana como é mais conhecida, no caso, rendeu vasta cobertura e comentários na imprensa à época, por ser "a primeira advogada indígena a falar ao STF", como escreveu a jornalista Flávia Tavares na notável reportagem "O dia da índia Joênia", publicada no jornal O Estado de São Paulo ${ }^{5}$. Para a ocasião, Joênia se paramentou com a beca usada pelos advogados na corte e pintou o rosto com traços vermelhos à maneira dos Wapichana. Começou sua fala na tribuna usando a língua materna. Flávia Tavares ressalta, entre outras coisas, o fato de um dos ministros do STF, Carlos Ayres Britto (relator do processo) ter dito que "até chorou" com a fala de Joênia, após abrir a decisão colegiada com o seu voto, favorável à demarcação. Na reportagem, também há menção à formação da advogada:

Sua comunidade decidira que ela deveria ser professora, para ajudar a educar os indiozinhos que lutariam pelas terras da reserva no futuro. Mas, quando a irmã mais velha morreu ao dar à luz, segundo Joênia por negligência do hospital, ela decidiu que queria fazer mais, à revelia dos líderes wapichanas. Seria advogada. Mudou-se com a mãe para a capital o pai ficou para trás por não aceitar viver na cidade grande. Estudou por conta e passou em quinto lugar no vestibular da Universidade Federal de Roraima. Na sala de aula, toda vez que a questão indígena era trazida à tona, os colegas olhavam imediatamente para ela. Eram, em sua maioria, filhos de políticos e fazendeiros.

Dois anos depois de formada, em 1999, foi chamada ao conselho dos "tuxauas", os líderes das comunidades - todos homens para receber as honrarias e a missão de cuidar de seus irmãos (TAVARES, 2008, p. J6).

É quase um truísmo afirmar que a questão territorial caminhou junto com o surgimento das organizações indígenas no estado de Roraima, mas me arrisco a supor que esse movimento atingiu o seu ápice com o sucesso da demarcação da TIRSS. As condicionantes impostas pelo STF, que limitam em muito a autonomia dos indígenas sobre a terra e reafirmam sua subordinação ao Estado brasileiro e seu aparato administrativo, provavelmente representam um ponto de inflexão na linha até então

\footnotetext{
${ }^{5}$ Edição de domingo, 31 de agosto de 2008 (Caderno Aliás, página J6).
} 
ascendente dos direitos territoriais indígenas, e não apenas em Roraima, uma vez que se tornariam o parâmetro para julgamento de outros casos.

Porém se hoje é possível falar na luta indígena enquanto uma série de conquistas, sobretudo territoriais, decorrentes de uma nova forma de organização política a conduzir a resistência desses povos, a partir disso que Santilli chama de instâncias supra-aldeãs (os Conselhos Regionais, organizados por sua vez em um Conselho Indígena de Roraima, sediado em Boa Vista), não se pode aqui deixar de mencionar, mesmo que brevemente, o histórico da longa opressão por que passaram os povos indígenas de Roraima. A promessa de melhorias, tanto de ordem pessoal quanto coletiva, oferecida por uma educação formal, oferece uma alternativa que se contrapõe diretamente ao sistema hierarquizado de exploração econômica, social e racial a que os indígenas foram submetidos. Essa exploração remete aos primeiros contatos com os povos europeus, mas estende-se ao longo dos séculos chegando até as portas dos dias atuais. Falar de tais temas é necessário, creio, para uma iluminação mútua entre diferentes épocas, dando força e sentido aos movimentos atuais e passados de resistência e emancipação.

\section{A exploração no rio Branco e os povos indígenas}

Para entender como se deram os primeiros contatos dos povos indígenas da região do rio Branco com os empreendimentos coloniais europeus, é preciso levar em consideração ao menos três fatores históricos: a) as expedições de escravização que partiam do lado brasileiro; b) as disputas pelos limites territoriais (fronteiras) entre diferentes projetos coloniais (Portugal, Espanha, Holanda, Inglaterra, França) - depois substituídas por litígios de fronteiras nacionais (Brasil, Venezuela, Suriname, Guiana, Guiana Francesa) - guardando-se as respectivas diferenças entre tais projetos; e c) as guerras intertribais locais e como os europeus se inseriram nelas. Certamente muitos outros fatores existem e são importantes para a compreensão do tema, mas é na intersecção desses três aqui elencados que se pode buscar uma síntese do que foi o caráter inicial da "colonização" da região.

A postura muitas vezes ambígua dos povos indígenas das Guianas em relação aos avanços das potências coloniais europeias - ora como suas presas, ora como seus aliados - é até hoje objeto de debates acadêmicos e acusações mútuas. Nádia Farage (1991), em sua pesquisa de mestrado sobre a ocupação colonial do rio Branco no séc. XVIII, demonstrou como Holanda, Portugal e Inglaterra utilizaram-se das relações mantidas com os povos indígenas da região para expandir e manter seus domínios, usando-os 
como "fronteira viva", ou ainda, "muralhas dos sertões". Em outras palavras, "a disputa em torno do território do rio Branco realizou-se através dos povos indígenas que o habitavam" (p. 18). Farage aponta, no entanto, que esses grupos indígenas também se utilizaram dos europeus - sobretudo de suas mercadorias, que trocavam por prisioneiros de guerra - em prol da expansão de suas redes de influência e circuitos de troca com outros povos.

Farage atesta que é consenso entre os "cronistas das Guianas" a "afirmação de que o apresamento de escravos para os holandeses era uma derivação das guerras intertribais" (p. 110). Os holandeses, que basearam sua política colonial não na conversão ou aldeamento dos índios, mas no estabelecimento de relações de escambo e tratados comerciais, conseguiram se inserir nos circuitos de troca indígenas e por fim "puderam controlar as guerras intertribais, retendo porém, o dispositivo guerreiro em seu próprio proveito" (p. 117). Os produtos manufaturados holandeses (armas de fogo, ferramentas de ferro) penetraram a região do rio Branco com intensidade a partir de meados do séc. XVII, chegando cada vez mais longe por meio das trocas intertribais, sendo esses objetos, e não a presença de tropas ou fortificações, que fizeram soar o alarme da "invasão holandesa" nos governos coloniais de Espanha e Portugal.

A efetiva ocupação da região por civis, entretanto, só teve início na segunda metade do século XIX, com a introdução da economia pecuarista. Farage e Santilli (1992) mostram como a ocupação das terras indígenas por fazendas de gado caminhou junto com a transformação desses indígenas em funcionários braçais das fazendas, o que implicou um confinamento duplo: tanto físico quanto social. Essa integração forçada, derivada da espoliação territorial e da desestruturação de seus sistemas sócio-naturais, fez com que os indígenas passassem a ocupar a camada inferior da hierarquia social local, que dependia inteiramente de sua mão-de-obra. Segundo eles:

no vale do rio Branco, a ocupação de terras fez-se ainda acompanhar de mecanismos de arregimentação da população indígena para as camadas mais baixas da sociedade regional que então se formava. $O$ processo de ocupação requeria $o$ confinamento territorial e, pari passu, a circunscrição de um lugar social para a população indígena. Duplo sítio, portanto ( $p$. 268).

Com a República, e ao longo de todo o séc. $\mathrm{XX}$, decretos e regulamentos serão usados para favorecer a elite regional no processo de ocupação fundiária e registros de posse no vale do rio Branco. Tais documentos faziam referência apenas marginal, quando faziam, às "malocas", "taperas" 
e "barracas" que indicavam a presença indígena (os "agregados") nos locais requeridos. Ali, os indígenas passavam a trabalhar para os novos "donos" do lugar. Alessandro Oliveira (2012), em sua pesquisa de doutorado, demonstrou como esse sistema de exploração do território (pastoreio) e do trabalho (baseado na relação entre o fazendeiro e o vaqueiro) é que organizou a invasão e a ocupação daquela região por uma população de nãoíndios, presidindo as relações destes com os indígenas. Essas novas regras de "convívio" acabaram produzindo forte impacto negativo sobre as formas indígenas de organização social e de relação com o território e o meio ambiente:

A invasão de fazendas de gado provocou uma série de impactos nas práticas indígenas de uso territorial. Enquanto o avanço do gado destruía as roças, o desenho das fazendas provocava uma série de constrangimentos à mobilidade dos índios e às suas práticas de tradicionais. Com as fazendas, surgiram proibições à prática de pesca com timbó, restrições do acesso aos lagos e outras fontes de água perenes, e o cerco de regionais também refletiu no progressivo escasseamento da caça. Além destes impactos sobre as práticas, o recrutamento de crianças indígenas para pretensamente "aprenderem" a lidar com o gado junto às famílias "civilizadas" na maior parte das experiências revelava o caráter servil do regime de exploração do trabalho que caracterizou as relações entre fazendeiros $e$ indios. Este foi um expediente também amplamente utilizado pelos posseiros, criando relações de compadrio que reforçava os laços clientelistas com os índios (p.62).

Lembranças do trabalho duro nas fazendas de gado permanecem vivas e são transmitidas para as novas gerações, sendo que pude conversar com alguns netos e filhos de indígenas que foram "escravo de fazenda". Nas falas de anciãos e lideranças, estes frequentemente insistem em mencionar que estão buscando "uma vida melhor" para seus filhos e netos (o que já conseguiram em muitos aspectos). Essas falas são movidas pela lembrança de um tempo não muito distante e não de todo superado, vivido por eles, de grande exploração e sofrimento, em que trabalhavam de sol a sol e conviviam com a fome, servidão e castigos físicos.

Em Roraima, o empenho de certas figuras socialmente engajadas da Igreja Católica foi realmente um fator fundamental de organização nos primórdios do movimento indígena. Quem se aprofunda mais nesses estudos sobre a origem do movimento indígena no estado de Roraima e sua ligação com a "ala progressista" da Igreja é Jaci Guilherme Vieira (2014), que 
prefere trabalhar com a noção de formação de uma consciência crítica indígena advinda dessa parceria, "a partir de uma série de projetos que visavam tanto a independência econômica como à formação política dos índios de Roraima" (p. 14). Vieira demonstra como inicialmente os propósitos da Igreja na região do rio Branco eram bem outros, aliados aos interesses das elites locais, mas a partir da década de 1960 os missionários de Roraima passaram a ver os povos indígenas como " $O$ verdadeiro oprimido na região" (p. 172) e mudaram consideravelmente sua postura, passando a denunciar as invasões e violências promovidas por fazendeiros, e a trabalhar em prol da emancipação política daqueles povos oprimidos pelos poderes locais, sobretudo advogando pela demarcação de suas terras e implementando os referidos projetos.

A noção de projeto, entretanto, fartamente utilizada entre os povos indígenas de Roraima, é duramente criticada por Maxim Repetto (2008) enquanto um elemento externo às tradições indígenas que, ao contrário de representar um planejamento autogerido do seu futuro, estaria substituindo e atualizando as práticas assistencialistas e tutelares dos órgãos indigenistas, configurando verdadeiros "mecanismos de mediação e de poder, uma vez que permitiram às agências indigenistas o acesso e $o$ controle sobre as comunidades indígenas" (p. 80). Mais do que uma acusação despropositada contra algumas lideranças ou organizações, essa crítica está diretamente vinculada àquela que aponta para as constrições impostas pelos reduzidos limites físicos das Terras Indígenas demarcadas e pela degradação de seu entorno, comprometendo gravemente a sustentabilidade (econômica, ambiental, cultural) das comunidades e obrigando-as a se adaptar a novas formas de subsistência (FRANK, CIRINO, 2010).

Apesar das ameaças representadas por novas configurações de poder político e econômico na dinâmica social indígena, as organizações indígenas do estado, por sua vez, permitem que as bases sociais (isto é, as comunidades indígenas) exerçam forte controle sobre as lideranças eleitas, ao contrário do que ocorre com os cargos da política partidária. É o que afirma Repetto, a respeito dessas organizações (formadas em maior parte pelos povos Macuxi e Wapichana):

Para os Makuxi, uma boa liderança indígena é aquela que manifesta e atua segundo as orientações das pessoas ou grupos que o elegeram. Reiteradas vezes ouvi lideranças refletirem a respeito do poder delegado a elas, aceitando-o, não tanto pelo interesse pessoal de aparecer publicamente, mas para levar avante o trabalho da comunidade. Quando a 
comunidade desejar, eles se dispõem a entregar os cargo sem rancores. Estes pronunciamentos são respeitados nas assembléias. Líderes autoritários e que não consultam as bases logo são vistos com desconfiança, e logo alguém enuncia: "será que quer ser mais que a gente?" (REPETTO, 2008, p. 115).

Após essa rápida abordagem de alguns aspectos da constituição do movimento indígena em Roraima, passo a debater, no próximo item, o papel da educação formal no processo de conquista da autonomia indígena, tomando como exemplo algumas de suas lideranças. Em princípio a educação escolar destinada aos indígenas ficou a cargo dos religiosos, enquanto isso era interessante para os governantes ${ }^{6}$, configurando um desenvolvimento paralelo a todo o processo de invasão e posterior retomada da terra. A escola indígena acompanhou as mudanças de postura e de propósitos das iniciativas de contato com os indígenas, num movimento que vai das tentativas de sua evangelização/catequização, passando pela "civilização" e formação de "trabalhadores úteis", para depois ter aos poucos a sua força apropriada e revertida pelos próprios indígenas, em favor daquilo a que chamaram a escola que queremos, chegando aos resultados atuais, ainda insatisfatórios, de uma educação escolar indígena diferenciada e bilíngue, mantida quase contra a vontade por um Estado cada vez menos interessado na diversidade cultural e no conhecimento indígena ${ }^{7}$.

\section{A luta indígena de Roraima e a educação formal}

O papel da educação formal no contexto de retomada de terras e direitos, que culmina com a demarcação da TIRSS, não é nada fortuito. Alcida Rita Ramos aponta para essa convergência entre a educação e autonomia política em uma passagem muito marcante de sua própria experiência de campo, na forma de um testemunho do que era e do que passou a ser a situação dos povos indígenas do Lavrado de Roraima com o contato interétnico e com suas organizações ${ }^{8}$. Em Boa Vista, ainda se podem

\footnotetext{
${ }^{6}$ Como escreve Jaci Vieira (2014): "No Rio Branco, região completamente destituída de políticas públicas, os religiosos tiveram o monopólio completo da educação até 1970, quando então o Estado assumiu para si essa responsabilidade, levado principalmente pelos conflitos entre a Igreja e os grupos de interesse local. Houve uma dispensa da Igreja dessa responsabilidade, com o objetivo explícito do próprio Estado de colocar sua proposta e tornar-se hegemônico via projeto educacional. O objetivo era claro: impedir mais do que nunca que as terras indigenas fossem demarcadas"(p. 131).

${ }^{7}$ Tratei do assunto escolarização e povos indígenas mais detalhadamente em outro artigo, no qual relaciono os debates em torno da implementação da escola indígena específica e diferenciada nas comunidades indígenas de Roraima com uma discussão mais ampla em torno da educação entre os povos indígenas, do ponto de vista de seus intelectuais (Lisboa, 2017).

${ }^{8}$ Assim escreve Ramos em seu texto: "...lembro-me dos Macuxi de Roraima quando comecei a fazer minha pesquisa de campo com os Yanomami, no fim da década de 1960. Eram humildes varredores das ruas de Boa Vista que mal ousavam levantar os olhos do chão e pareciam querer fazer-se invisíveis para aquele mundo hostil que
} 
perceber os ecos da longa marginalização dos indígenas, mas também é possível inferir o quanto essa exclusão era mais acentuada décadas atrás, ou como ela foi se transformando com o tempo. Ramos enfatiza que algo mudou do final da década de 1960 para cá, mostrando que os povos indígenas haviam, ao final desses quarenta anos, conquistado protagonismo, "agencialidade e força política", nas palavras da antropóloga, dando como principal exemplo a vitória no processo de demarcação da TIRSS. Por fim, a "educação formal" é apontada por Alcida Ramos como fator crucial nessa mudança, assim como uma das principais expressões de seus resultados:

Tema quase inexistente há apenas umas três décadas, a educação, inclusive de nível superior, vem tomando um espaço substancial nas preocupações de índios e não índios. Talvez seja neste campo que a agencialidade indígena se faz sentir com mais vigor (RAMOS, 2010, p. 29).

Com a luta jurídica pela demarcação e homologação da TIRSS, todo um vocabulário jurídico em torno da noção de Terra Indígena e seu processo demarcatório pelo Estado brasileiro passou a fazer parte das falas de jovens e adultos minimamente envolvidos com o movimento indígena em Roraima. Nas palavras das lideranças mais antigas, a memória desse longo processo eivado de conflitos e de violência ${ }^{9}$ contra os indígenas se mistura com as referências aos ancestrais míticos, principalmente Makunaima, fazendo com que o tempo da luta e o tempo do mito se embolem e se alimentem mutuamente nos seus discursos, como neste exemplo colhido pelo jornalista Felipe Milanez (2006):

A palavra "homologação" ficou recorrente nos idiomas dos povos, inspirou letras de músicas, nomeou uma aldeia e até animais domésticos. No pátio central da aldeia Maturuca, foi inaugurada uma escultura para marcar a data da homologação. De acordo com o tuxaua Jacir José de Souza, chefe da

\footnotetext{
ao mesmo tempo os envolvia e os rechaçava acintosamente. Viviam então o lado mais sombrio da fricção interétnica, relegados à absoluta marginalidade social, cultural e econômica. Quarenta anos depois, os mesmos Macuxi, aliados aos Wapichana e a outros povos do Lavrado de Roraima, eram os protagonistas de uma das mais célebres batalhas judiciais dos tempos modernos, ao defender, em igualdade de condições, os seus direitos territoriais contra empresários da agroindústria que ocupavam ilegalmente suas terras. Os esforços dos advogados indígenas foram cruciais para que os habitantes tradicionais da terra indígena Raposa-Serra do Sol saíssem vitoriosos na decisão do Supremo Tribunal Federal que confirmou a validade de sua terra indígena em forma contínua e afastou invasores arrogantes e belicosos [...]. A educação formal transformou aquela invisibilidade Macuxi numa demonstração exemplar de agencialidade e força política"(RAMOS, 2010, p. 28).

${ }^{9}$ A disputa, mais do que um embate de ideias, envolveu atos de violência por parte de fazendeiros, que incendiaram e destruíram locais estratégicos para os indígenas dentro da TIRSS, como o Centro de Formação e Cultura, uma igreja, um hospital e uma escola, como denunciou a respeito o na época presidente da Confederação Nacional dos Bispos do Brasil (CNBB), Dom Geraldo Magella, na seção Tendências/Debates do jornal Folha de São Paulo, datado de 09 de outubro de 2005 (http://wwwl.folha.uol.com.br/fsp/opiniao/fz0910200509.htm).
} 
Maturuca, foi a vitória de uma luta de mais de 30 anos. Como símbolo, foi erguida a figura de Makunaima, o deus vindo do Sol, que transformou a vida e o território. "Ele foi uma liderança forte, não tinha medo, e isso deu força para os seus netos que somos nós", diz Jacir. "Essa lembrança nos fez lutar para defender o nosso direito, a luta até o último índio" (p. 15).

Como o marco de pedra no centro da comunidade Maturuca indica, a questão da terra ficaria gravada de forma permanente na memória e nas ações seguintes do movimento indígena, e isso repercutiu também no que se refere à educação formal e ao ensino superior. Assim como Joênia Wapichana buscava inicialmente melhorar as condições de seu povo ao optar pelo curso de direito, os filhos e netos de importantes tuxauas (que são conhecidos como "as lideranças") levam consigo o espírito de luta pela causa indígena ao ingressarem na faculdade, um ideal que está presente na hora de escolher o curso e a carreira profissional que vão seguir. É o que se depreende da fala de muitos jovens ligados ao movimento indígena no estado. Como exemplo, trago o depoimento da estudante indígena de agronomia, Maria das Dores, do povo Macuxi, que entrevistei em fevereiro de 2016 na biblioteca da Universidade Federal de Roraima (UFRR):

Eu escolhi Agronomia para a situação do meu povo. Eram duas opções que eu tinha, Direito e Agronomia. Para a luta dos povos indígenas, que era o Direito, e a Agronomia para $o$ desenvolvimento da comunidade. Então eu escolhi Agronomia para trabalhar na terra indígena junto com o povo.

(...)eu fui indicada desde o curso técnico de Agronomia. Fui escolhida pela liderança com mais 20 jovens que vieram para a escola de Surumu, Centro Indígena de Formação, que é da liderança da Raposa Serra do Sol, e daí eu resolvi fazer o vestibular e consegui entrar, que eram cinco vagas para indígenas e eu fiquei em quarta colocada [Entrevista com Maria das Dores Lima da Silva, 31, realizada em 19/02/2016, na biblioteca da UFRR].

$M^{a}$. Das Dores expõe, em seu dilema entre cursar direito ou agronomia, o vínculo fundamental entre a terra e a causa indígena como um todo. A produção de alimentos - um dos argumentos que os fazendeiros invasores utilizavam para permanecer no local - tornou-se um dos novos desafios com a demarcação da TIRSS. Não que os indígenas não produzissem alimentos antes, mas isso agora passou a ser tratado em outros termos, 
numa forma de rebater as acusações preconceituosas dos seus adversários, que continuaram existindo após a desintrusão. É como se precisassem legitimar novamente - ou permanentemente - o uso de uma terra que sempre foi sua:

Depois da demarcação da Raposa da Serra do Sol, e depois da retirada dos arrozeiros, dos fazendeiros, a questão que os brancos passavam no jornal e publicavam muito [era] que os indígenas estão morrendo de fome, não tinham nada pra comer, mas tudo isso é mentira. Os indígenas nunca passaram fome, os brancos nunca deram comida pra eles na verdade, nunca ofereceram nada. Então a gente queria a terra para retomar de volta as criações, as plantações que estavam sendo poluídas, e o meu objetivo de Agronomia é isso. Desmentir todo esse jornal, esse povo político que ficam mentindo nas televisões.

(...)E não sou só eu que estou de indígena na Agronomia, são cinco da Raposa Serra do Sol que estão fazendo Agronomia, Zootecnia... que já estão prestes a concluir. Então a gente focou muito sobre esses políticos que ficam mentindo e a gente quer desenvolver na Raposa Serra do Sol essa produção, a autossustentação do nosso povo [Idem].

A família de Maria das Dores mora da comunidade indígena Lilás (da qual sua mãe é a tuxaua), no município de Uiramutã, dentro da TIRSS. "Eu também sou da comunidade, estou aqui com o objetivo do estudo", afirma a estudante, que além das atividades acadêmicas milita no movimento indígena, participando das atividades desenvolvidas pelas organizações, como reuniões e manifestações - coisas que, aos poucos fui percebendo, fazem parte da rotina de muitos outros estudantes indígenas. Encontrei-me com Maria das Dores em uma dessas manifestações, em frente ao Fórum Bento de Faria, da Justiça Federal em Boa Vista. Era uma manifestação muito bem organizada, com faixas, danças, cantos e orações, debaixo do sol forte daquela manhã de fevereiro, tudo sem atrapalhar o movimento de entra e sai no Fórum - atendendo a uma determinação que partiu de dentro do prédio para não bloquearem a entrada. Um dos manifestantes cuidava exclusivamente para que as pessoas atravessassem a rua na faixa de pedestres. Falaram-me que tal grau de organização e persistência devia-se à presença dos indígenas da região das serras, que seriam mais acostumados à mobilização e à luta. 
A sede administrativa do Distrito Sanitário Especial Indígena Leste de Roraima (DSEI/Leste), a menos de um quilômetro dali, estava ocupada por centenas de indígenas, um grande número deles vindo de comunidades distantes, com famílias inteiras instaladas no local. Manifestavam-se contra a indicação política do novo coordenador distrital ${ }^{10}$, alegando que as comunidades não haviam sido consultadas, como manda o direito à consulta prévia garantido pela Convenção 169 da OIT. Perto do meio dia partimos em caminhada até lá, onde foi exposta a situação jurídica da "ocupação" e o mandado de reintegração de posse da sede impetrado pela AGU.

Neta do conhecido tuxaua Sr. Jacir, José de Souza, um dos nomes fortes da história do movimento indígena em Roraima e ainda hoje uma grande autoridade na região das serras, Maria das Dores fala sobre esse aprendizado que teve dentro da "luta"11 indígena e junto com sua família:

eu desde pequena tenho seguido a cultura dos meus avós. Eu sempre gostei de luta, de dança, de pinturas, de comida, da natureza, então eu sempre busquei preservar a minha aldeia. $O$ meu avô, antes, a gente sofreu muito na luta com os fazendeiros, os garimpeiros, e assim fui crescendo vendo essa luta dele, né. Então eu faço parte da organização do CIR, também trabalho no Movimento das Mulheres Indígenas de Roraima junto com a minha mãe, que ela é a liderança, tuxaua da comunidade e eu gosto muito, assim, luto. Não só com o povo daqui de Roraima, mas tenho contato com vários outros indígenas de outros estados e vejo essas lutas de sofrimento sobre a terra, sobre a demarcação, então eu sempre admiro muito quem luta e vou continuar nessa luta [Idem].

A busca pela formação superior é assim mobilizada em função da "luta", por meio de cursos universitários que forneceriam o instrumental necessário para o fortalecimento do movimento, das comunidades e das lideranças indígenas. O sentido que Maria das Dores dá ao termo "luta" - inicialmente fazendo referência à cultura de seus avós, à dança, pinturas, comida, natureza; posteriormente envolvendo-se com "outros indígenas de outros estados" e suas "lutas de sofrimento sobre a terra" - não é um sentido

\footnotetext{
${ }^{10}$ Ver cobertura do caso na imprensa local: http://gl.globo.com/rr/roraima/noticia/2016/02/protesto-de-indiosmantem-sede-do-dsei-leste-ocupada-em-roraima.html

${ }^{11}$ Quanto à provável dúvida a respeito da palavra "luta", se é categoria nativa ou analítica - uma vez que os antropólogos se acostumaram a tratar essas duas possibilidades em termos antagônicos e excludentes (assim como pensamento e ação) - pergunto de volta: por que não tratá-la como uma categoria da análise nativa, um elemento presente e vigoroso de suas reflexões existenciais e políticas, além de um instrumento de ação e mobilização muito eficaz para os indígenas?
} 
estanque, ao contrário, promove no decorrer mesmo de sua fala uma ampliação, uma trajetória semântica. Sua fala a retrata como se estivesse partindo da esfera de sua família, da comunidade, e se unindo a uma luta mais ampla para depois, já de volta, afirmar "e vou continuar nessa luta". Trajetória parecida com a que se exige de um acadêmico indígena. Formarse em Agronomia é assim um investimento na autossustentação do seu povo (um dos novos desafios apontados por lideranças indígenas após a demarcação da TIRSS) ao mesmo tempo que apenas mais uma etapa no aprendizado vivenciado na "luta".

Muitas vezes a necessidade de qualificação profissional surge em decorrência do próprio cargo ou função exercida no movimento indígena, que por si só exige um permanente investimento na formação pessoal. Quando conversei com Leuma Ferreira, à época secretária adjunta na Secretaria do Índio do estado de Roraima, foi bem isso que ela me explicou, tomando seu caso pessoal como exemplo. Leuma já foi tuxaua da comunidade e coordenadora da Associação dos Povos Indígenas de Roraima (APIR), além de já ter trabalhado na Coordenação Indígena do município de Boa Vista, ates de chegar na Secretaria do Índio. Ao longo dessa "carreira" de liderança indígena, ocupando cargos seja no movimento ou na administração pública ${ }^{12}$, a escolha pelos cursos de Administração e Direito é tratada por Leuma menos como preferência individual do que como necessidade:

Bem, eu nasci na Comunidade Indígena Vista Alegre, na Terra Indígena São Marcos, e em 2005 eu fui tuxaua da comunidade. Em dois anos e meio, em 2007, eu ganhei para coordenação da Associação dos Povos Indígenas do estado de Roraima, a APIR. E de lá, como a Associação tem a sede aqui em Boa Vista, eu vim para assumir na sede, passei três anos na Associação, e na Associação eu senti essa necessidade de ter uma formação. Como indígena, a gente sair e representar em vários estados, né, buscar também o interesse da população indígena, e de a gente poder debater os assuntos no mesmo nível. E foi a partir desse momento que eu senti essa necessidade e o curso que eu

\footnotetext{
12 Jean Paraizo Alves, em sua tese de doutorado, também notou essa alternância de dirigentes indígenas entre as organizações indígenas e os órgãos públicos. Alves defende que, com a redemocratização do País após a ditadura, aumentou a presença de indígenas nas administrações locais, seja em cargos eletivos ou em cargos e funções "comissionadas". Como consequência, nesses estados e municípios, "as 'metáforas bélicas' de confrontação entre indígenas e Estado, mencionadas até a exaustão por ativistas dos movimentos sociais nos anos 1980, perderam força, dando lugar ao diálogo, e em alguns casos para o simulacro de diálogo entre cidadãos indígenas, políticos eleitos e burocratas" (ALVES, 2007, p. 90). A Secretaria Estadual do Índio, onde Leuma trabalha, é de fato um lugar em que metáforas bélicas como "Iuta" são frequentemente substituídas por "diálogo" ou, o que é mais comum, pelo seu simulacro. Não obstante, como se viu no depoimento anterior, seria errôneo afirmar que em Roraima a "luta" perdeu força, seja na prática ou no discurso, uma vez que segue viva e forte nas organizações que se propõem a uma postura mais combativa.
} 
me identifiquei foi com Administração. E cursei Administração; no ano passado que eu consegui minha formação. Não consegui antes porque a minha família não tem condição financeira de me ajudar, mas graças a Deus eu comecei a trabalhar e consegui essa formação em Administração.

(...) E em seguida já comecei a fazer Direito também por essa necessidade de a gente usar e saber dos nossos direitos, de levar para os demais povos, que muitas vezes, por preconceito, por alguma coisa assim a gente não consegue se defender ou buscar um tipo de direito que é nosso. Fica muito solto. E com relação ao preconceito, a gente passa, mas isso também vem da gente. Se a gente deixa se abater, se a gente se sente fragilizado, isso aí, para mim, graças a Deus, eu levei tranquilo. Também a minha formação é couching, né. Fiz couching em Brasília e fiz executive couching esse ano já [Entrevista com Leuma Ferreira realizada em 12/02/2016, na Secretaria do Índio do Estado de Roraima].

Os períodos de formação e exercício da liderança muitas vezes precisam ser intercalados, já que o estudo demanda quase sempre que se more em Boa Vista - o que favorece o trabalho em organizações mas impede que se exerça o cargo de tuxaua, função esta que Leuma pensa em voltar a exercer, dizendo que "se tiver oportunidade de ser tuxaua estou pronta para ir e enfrentar". Afirmo que ela seria uma tuxaua superespecializada, devido a toda essa formação e experiência que acumulou. Por ser mulher, Leuma já venceu a eleição para tuxaua uma vez, concorrendo com vários homens, no que entende ter sido uma escolha da comunidade para enfrentar o problema do alcoolismo, que afeta muitos homens inclusive os que são indicados para tuxaua.

Leuma pretende usar os conhecimentos que adquiriu em prol do desenvolvimento e da união de sua comunidade, que hoje está, como muitas outras, em uma relação prejudicial de dependência econômica de governos e políticos: "a minha visão é de voltar para comunidade e ter essa visão de produção junto com a população de uma forma coletiva que dá para crescer, dá para melhorar, mas as dificuldades elas surgem quando a gente impõe". A postura afirmativa se manifesta também no meio acadêmico, enquanto estudante de graduação, exigindo o cumprimento dos direitos garantidos aos indígenas, como o respeito a sua cultura. Leuma estuda Direito na faculdade Estácio/Atual, uma instituição particular, pagando as mensalidades do próprio bolso, como fez no curso anterior, Administração. 
Quando perguntei se a Estácio tinha um levantamento da quantidade de alunos indígenas matriculados, ela me respondeu assim:

Ainda não tem. Aí eu até falei para eles, sugeri que a gente poderia estar vendo quantos indígenas tem. Falei também que na Administração a minha colação foi normal, como todos, agora em Direito eu quero uma diferenciada. E eles "Mas por quê?", e eu disse "Porque eu sou indígena e eu tenho o meu direito". [risos] Aí eu disse que eu quero estar a caráter, ter uma colação diferenciada, e aí disseram "É, a gente pode ver" e eu disse que "Não, mas eu tenho, se eu quiser fazer assim eu tenho direito", né, é a minha escolha. (...) Aí eu falei para eles "É por isso que eu estou fazendo Direito, né" [Idem].

Ambos os exemplos aqui expostos, Maria das Dores e Leuma, são antagônicos e complementares: a forma de atuação (uma mais institucional e outra mais ativista) e a organização de que fazem parte (CIR e APIR) apresentam diferenças consideráveis entre si. Uma é uma jovem de trinta e poucos anos, a outra já tem mais idade e um filho de vinte. Uma está na Universidade Federal, a outra estuda em uma particular. Mas essas duas mulheres são também pontos referenciais diversos de um mesmo movimento, compartilham o discurso politizado, a afirmação dos direitos indígenas e o desejo de trabalhar para o desenvolvimento de sua comunidade. Ambas usam a universidade não apenas como um investimento pessoal para alcançar o sucesso profissional e o bem estar econômico, mas principalmente com o intuito de fortalecer a "causa comum" dos povos indígenas. $O$ ingresso na universidade é tratado por elas como um acontecimento posterior ao engajamento nas comunidades e organizações, e geralmente a decisão pela vida acadêmica conta com o apoio destas para se concretizar.

Se a educação formal é, já faz algum tempo, um elemento indispensável na luta do movimento indígena em Roraima, e se seus quadros cada vez mais são investidos desse tipo de formação, isso não começa com lideranças ou seus descendentes entrando nas universidades. Muita coisa teve que acontecer antes que os cursos da UFRR abrissem vagas específicas para indígenas através de um vestibular diferenciado, ou que se criasse 0 Instituto Insikiran, ou para que se firmasse um convênio entre as organizações indígenas e algumas instituições particulares de ensino superior (episódios hoje centrais para a educação indígena em Roraima e dos quais tratei em minha tese, mas que este artigo não dá conta de abordar). 
Creio ser necessário, antes disso, voltar alguns passos e retomar o que foi a luta indígena pela construção de uma educação escolar diferenciada, ou seja, de uma escola que seguisse os seus propósitos autônomos e valorizasse as culturas e línguas indígenas. $O$ quadro relativamente animador que um observador como eu pude encontrar nos últimos anos decorre de um longo processo de mobilização, busca de aliados e negociações, em que transformações locais ocorrem simultaneamente a outras de âmbito nacional na área da educação, tudo isso sendo significado pelos indígenas de Roraima em novas práticas e discursos.

\section{Escola e organizações indígenas: locais de formação e resistência, motor de transformação e "contradominação"}

A professora Maria Auxiliadora de Souza Melo é quem nomeia a Biblioteca Central da UFRR, num explícito reconhecimento, entre outras coisas, pelos seus esforços na criação do Instituto Insikiran ${ }^{13}$. Antes de realizar sua pesquisa de mestrado e se mudar para Boa Vista, Auxiliadora entrou em contato com a educação indígena em Manaus, ainda nos anos 1990. Ali, enquanto lecionava no ensino médio, começou a assessorar organizações indígenas, dentre as quais o Movimento de Estudantes Indígenas do Amazonas (MEIAM), formado por jovens indígenas que estudavam em Manaus, e assim passou a se envolver com as dificuldades e reivindicações de acesso e permanência de indígenas na universidade. Foi nas atividades junto ao MEIAM que ela pode "perceber o dilema vivido pelos jovens indígenas: estudar na cidade para ajudar seu povo a melhorar seus instrumentos de reivindicação por direito, inclusive o de educação intercultural' (MELO, 2000, p. 14).

Foi com a experiência acumulada em Manaus que Maria Auxiliadora chegou em Roraima, em março de 1997, após ter participado de dois encontros organizados pelo CIR dois anos antes. Percebeu que os conflitos no estado tinham "a terra como pano de fundo" (p. 17), o que não era diferente ao se tratar do problema das escolas. Auxiliadora voltou-se para a

\footnotetext{
${ }^{13}$ No Diário Oficial de Roraima de 09/09/2003, à p. 21, por ocasião do Prêmio Notoriedade Cultural, entregue pelo governo do estado, consta a seguinte nota a respeito da Professora Auxiliadora: "Maria Auxiliadora de Souza Melo, amazonense, mestre em Antropologia, desenvolvia suas atividades profissionais na Universidade Federal de Roraima. Em 2000, por iniciativa de algumas organizações indigenas, a UFRR realiza cursos de extensão como parte do processo de formação continuada para professores indígenas, culminando com a instalação do núcleo Insikiran cujo objetivo maior foi criar o Curso de Formação Superior de Educação Intercultural Indígena, iniciado em julho de 2003. Durante todo esse processo, um nome deve ser mencionado quando se falar em núcleo Insikiran. Trata-se da professora Maria Auxiliadora que à frente da coordenação dos trabalhos fez este sonho se transformar em realidade. E, como num misto de missão cumprida e a capacidade de que tudo poderia ser concretizado, Maria Auxiliadora falece prematuramente dias após a aula inaugural do Curso de Formação Superior de Educação Intercultural Indígena" (Fonte: http://imprensaoficial.hospedagemdesites.ws/diarios/doe20030909.pdf).
} 
educação indígena em Roraima, e esse foi o tema de seu mestrado em Educação pela Universidade do Amazonas, tendo realizado sua pesquisa num momento em que a universidade ainda era uma caixa hermética para quase todos os indígenas de Roraima. Ainda no ano de 1995, na XXIV Assembleia Geral dos Tuxauas, por exemplo, Auxiliadora destacou que, para o movimento indígena do estado, "a Universidade está se revelando um caminho errado, pois demonstra preconceito cultural" (p. 19), como fizeram constar no relatório final da reunião.

Ao optar pelo mestrado, Maria Auxiliadora já estava certa de que iria trabalhar junto às principais organizações indígenas voltadas para o assunto, o CIR e a Organização dos Professores Indígenas de Roraima (OPIR), "a fim de identificar os processos de construção da escola indígena, como possibilidade de autonomia e de afirmação de identidade, na dinâmica das relações interculturais" (p. 20). Além disso, Auxiliadora apontava para a natureza formadora dessas organizações indígenas em suas reuniões e atividades, desenvolvidas com base em valores que ela define como consciência coletiva e trabalho comunitário. Nos termos dessas organizações, a educação indígena é algo que se dá pela socialização. Ou seja, ao se tornarem espaços de engajamento e participação, "CIR/OPIR constituem-se em escolas culturais de formação, onde são preparadas as lideranças para assumirem o gerenciamento dos novos projetos das malocas e das próprias organizações" (p. 24). Submetidos a uma escolarização que nada mais era do que outra face da dominação colonial - a sua face epistêmica, voltada para o "ensinamento de valores alienígenas" (p. 26) -, a resposta dos povos indígenas de Roraima veio na forma que lhes é característica, a união e valorização de suas diferentes culturas no combate à discriminação. Assim, "os povos Macuxi/Wapichana uniram-se pelas circunstâncias coloniais num projeto de organização indígena moderno, cujo símbolo principal é a resistência" (p. 10).

Como escreveu Auxiliadora em sua dissertação, a escolarização dos Macuxi e Wapichana pode ser lida sob a chave da contradominação, ou seja, o aproveitamento de brechas, ou fissuras, existentes no sistema de dominação colonial contra esse próprio sistema - o mesmo que se dá com a adoção da linguagem formal dos direitos por grupos oprimidos - numa espécie de jogo:

a problemática atual da educação escolar dos povos Macuxi e Wapichana de Roraima, articulada a paradigmas oficiais de educação, considerando que na história da colonização a dominação não se dá de forma fechada mas, ao contrário, é 
tecida com possibilidades de "fissuras", que canalizam movimentos de "contradominação", quando, por exemplo, o colonizado utiliza-se da língua do colonizador para reclamar direitos que lhe foram negados, culminando assim num "sistema de jogo" articulado na ordem social dos povos Macuxi e Wapichana em um ritmo de disputa, assimilação e conquistas (p. 5-6).

Penso que é isso o que Antonella Tassinari (2001) quer dizer ao sugerir considerarmos a escola indígena como uma fronteira, ou seja, "um espaço de encontro entre dois mundos, duas formas de saber ou, ainda, múltiplas formas de conhecer e pensar o mundo: as tradições de pensamento ocidentais(...) e as tradições indígenas" (p. 47). Tassinari defende que, para os povos que passaram por processos de escolarização, a escola não é algo totalmente alheio e nem está completamente inserida nas culturas indígenas, mas "é como uma porta aberta para outras tradições de conhecimentos, por onde entram novidades que são usadas e compreendidas de formas variadas" (p. 50). Do ponto de vista da antropologia, por sua vez, a escola indígena seria ainda uma "janela aberta para novos horizontes", permitindo-nos pôr em perspectiva "nossos próprios mitos científicos" (Idem). Inspirada no modelo de fronteira étnica de Fredrik Barth, em que a definição de um grupo tribal dá-se mais por suas relações sociais (interétnicas) com outros grupos do que por seu escopo cultural interno, Tassinari é clara ao retratar a escola indígena como "espaço de interação e contato entre populações, onde há fluxo de pessoal e conhecimento e onde as diferenças sociais são construídas" (p. 64-5). Essa visão traz a vantagem de evitar que vejamos a escola como um objeto estanque, unidimensional e unidirecional, pois como fronteira ela permite fluxos e, para continuar no jargão da mecânica dos fluidos, torna possível uma certa "osmose" de saberes e pessoas.

Concordo que a escola seja esse espaço de trocas e que ela funcione como portas e janelas importantes nesse vai e vem. Mas acredito que, mais do que um espaço de fronteira ou uma abertura por onde passam diversas substâncias, a escola indígena funcione como um motor, sendo ela mesma a propulsora de forças para fora e para dentro da comunidade, podendo "girar" em sentidos ou funções diversas - trabalhando ora para a imposição colonial de matérias estranhas ora para a construção da autonomia indígena.

Levando à frente a noção de fronteira, o que proponho é ver a escola indígena como um motor de transformação, mas não nos moldes daquilo que o Ocidente passou a conceber como "transformação histórica", um 
processo inexorável no tempo (com versões à direita e à esquerda) cuja face, para os indígenas, foi sempre tenebrosa, a representar de fato o fim da sua história, seja pela aniquilação ou pela assimilação completas ${ }^{14}$. Não se trata aqui, portanto, de praticar uma história que se impõe sobre (tanto no sentido de eventos que agem sobre eles quanto no de uma disciplina que trata deles) os indígenas, vendo-os enquanto sujeitos passivos ou apenas vítimas (CARNEIRO DA CUNHA, 1992; SCHWARCZ, 2005). E tampouco se trata da emergência de um "sujeito histórico consciente", até então preso às amarras ideológicas da dominação, ou outras "categorias mentalistas" utilizadas à exaustão pelas pedagogias críticas "progressistas", como bem apontou Hugo Assmann (1993), nas quais "o corpo fica reduzido a signo de si mesmo" (p. 75).

Em vez disso, refiro-me àquilo que Lília Moritz Schwarcz (2005, p. 130) define como as "formas indígenas de pensar e fazer história - um regime de historicidades próprio -, uma outra história". Essa outra historicidade parte de uma noção de transformação que está de acordo com as características inerentes aos sistemas cosmológicos e sociais dos povos indígenas, uma variante daquilo que alguns etnólogos, a partir de Claude Lévi-Strauss, entenderam como a "lógica das transformações míticas" (ALMEIDA, 2008, p. 169). Tais transformações, como bem já foi observado, partiriam de um sistema de significados e posições que faz da diferença entre seus termos, isto é, dentre outras oposições, também aquela que passou a existir entre índios e brancos, o motivo e motor de sua continuidade (LÉVI-STRAUSS, 1993).

Mais do que uma conciliação apaziguadora nos termos de a estrutura é histórica, a história é estrutural, como proposto por Marshal Sahlins (2003, p. 180), no caso da Educação Escolar Indígena trata-se de fazer o motor girar ao contrário: a própria transformação é que é transformada; de um processo de assimilação etnocida, que passava pela aniquilação das formas e dinâmicas indígenas de vida-conhecimento ${ }^{15}$, para um movimento de construção da autonomia (política, econômica, linguística etc.) dos povos

\footnotetext{
${ }^{14}$ Joana Overing apontou para esse caráter de natureza hierárquica contido em nossa teoria do tempo, mais precisamente em seu elemento progressivo, que dá à passagem do tempo um efeito cumulativo e valorativo: "Daí a noção de que o que vem depois pode ser encarado como melhor. Essa crença no poder concedido pelo tempo linear progressivo tem implicações para a teoria política: dela deriva-se a ideia de que é natural que os Estados nacionais se tornem maiores e as civilizações se tornem melhores. Segundo a doutrina colonialista, os maiores e mais poderosos são os mais avançados, não apenas em tecnologia mas na sequência temporal' (OVERING, 1995, p. 131).

${ }^{15}$ Quando falo em vida-conhecimento, refiro-me explicitamente a Hugo Assmann, quando este afirma que "existe uma co-gênese das formas de aprendizagem com as formas de vida", ou ainda, que "existe um total entrelaçamento entre processos vitais e processos de aprendizagem - ou para ser mais enfático ainda: que os processos vitais se constituem e subsistem enquanto uma permanência e expansão cognitiva continuada" (ASSMANN, 1996, Prólogo).
} 
indígenas, em que educação, terra e direitos (elementos que as ciências coloniais souberam separar, mas que a luta-resistência indígena em Roraima, como demonstrado aqui, soube reunir outra vez) são parte de um mesmo processo vital, corpóreo e espiritual de relação com o mundo.

Com a ideia de inverter o "motor de transformação" do colonialismo, portanto, não pretendo um retorno às categorias mecanicistas que dominaram o início das ciências sociais, como a solidariedade mecânica de Durkheim, por exemplo, ou ainda a noção mais refinada de megamáquina, apresentada por Lewis Mumford (2010). Refiro-me antes a uma concepção dinâmica e histórica de sociedades (especificamente de certas sociedades indígenas) que buscam redescobrir e reconstruir a si mesmas em face de (ou contra) um passado colonial cujas forças ainda se encontram em plena atividade, a cobiçar suas terras, discriminar suas culturas e constringir seus direitos.

Esta máquina colonial a que me refiro é aquela que Darcy Ribeiro chamou de "moinhos de gastar gente" ([1995] 2006, p. 95), e que Pierre Clastres chamou de "máquina de destruição dos índios" ([1974] 2004, p. 82), o motor com o qual foram gestados os impérios coloniais, as potências europeias e as nações sul-americanas. Parar as pás desse moinho, ou ainda, fazê-las girar ao contrário, é aquilo que Maria Auxiliadora de Souza Melo, em seu pacto de vida com os povos indígenas de Roraima, tão bem soube definir enquanto movimentos de "contradominação", noção esta que, embora original e advinda do intenso convívio com os movimentos indígenas, nem sempre tem sua densidade teórica e analítica devidamente reconhecida. Tal movimento, que parece ter um alcance maior para este contexto do que a simples ideia de resistência, vez que é potência criativa e não apenas negativa, se dá por meio tanto das lutas incessantes dos indígenas quanto de suas danças e rezas, do parentesco e do cultivo da terra, tendo hoje na educação escolar indígena (ou seja, nas transformações que os povos indígenas estão fazendo sobre a escola) sua face mais visível.

\section{Considerações finais}

Na etapa atual da história dos povos indígena em Roraima, o encontro com a educação formal e a construção da Educação Escolar Indígena está em plena atividade, situa-se entre suas principais preocupações e exerce considerável força em seu movimento político e organizações. Tal etapa culmina até o presente momento com o acesso às universidades, para o que a grande referência é a Universidade Federal de Roraima, seja por seu tamanho e status, pela quantidade de indígenas matriculados ou pelas políticas de acesso desenvolvidas. O exemplo de Joênia Wapichana, assim 
como o de muitas outras mulheres (como Maria das Dores Lima da Silva e Leuma Ferreira), e homens indígenas, permite-nos perceber o importante vínculo entre a educação formal e as lutas pela terra e por direitos empreendidas pelas organizações indígenas de Roraima.

Dessa forma, escolas indígenas e universidades passam a compor o novo cenário (somando-se às tradições e aos modos e meios de vida ancestrais de sua cultura, mas também a outros elementos como igrejas, Estado e organizações) em que esses povos originários vivem e constroem seu cotidiano, assim como representam mais um ingrediente para as lutas indígenas no século XXI. Ao contrário do que propôs Lévi-Strauss (1989), neste caso a bricolagem indígena não se daria no plano da reflexão mítica (que decorre menos do improviso do que de um relação ancestral com a terra e todos os seres), mas seria feita a partir dos cacos do mundo moderno e sua montanha infinita de resíduos, para usar uma imagem benjaminiana, em meio aos quais reconheceríamos os escombros de uma escola-padrão do século $\mathrm{XX}$, e outras coisas que foram impostas aos indígenas ao longo de tanto tempo e que a própria "civilização" vai descartando em volume cada vez maior. Ali, de vez em quando, encontra-se um manual de direito constitucional, um galão vazio de agrotóxico, um telefone celular de modelo ultrapassado, prontos a serem recolhidos e utilizados da maneira que seus antigos donos menos esperam.

\section{Referências}

ALMEIDA, Mauro William Barbosa de. A fórmula canônica do mito. In QUEIROZ, Ruben Caixeta; NOBRE, Renarde Freire (Organizadores). LéviStrauss. leituras brasileiras. Belo Horizonte: Ed. UFMG, 2008.

ALVES, Jean Paraizo. Em busca da cidadania: escolarização e reconhecimento de identidades indígenas em dois países americanos (Brasil e México). Tese de doutorado em Ciências Sociais (Estudos comparados sobre as Américas), CEPPAC, UnB. Brasília, 2007, 349 páginas.

ASSMANN, Hugo. Paradigmas educacionais e corporeidade. Piracicaba, SP: UNIMEP, 1993.

Metáforas novas para reencantar a educação; epistemologia e didática. Piracicaba, SP: UNIMEP, 1996.

BAINES, Stephen Grant. Identidades e protagonismo político indígena no Brasil após a Constituição Federal de 1988. In PIMENTA, José; SMILJANIC, Maria Inês. Etnologia indígena e indigenismo. Brasília: Positiva, 2012a. 
O movimento político indígena em Roraima: identidades indígenas e nacionais na fronteira Brasil-Guiana. Caderno CRH, Salvador, v. 25, n. 64, p. 33-44, Jan./Abr. 2012b.

CLASTRES, Pierre. [1974] Do etnocídio. In CLASTRES, Pierre. Arqueologia da violência - pesquisas de antropologia política. Prefácio de Bento Prado Jr.; tradução de Paulo Neves. São Paulo: Cosac \& Naify, 2004.

CUNHA, Manuela Carneiro da. Introdução a uma história indígena. In CUNHA, Manuela Carneiro da (org.). História dos índios no Brasil. São Paulo: Fapesp/SMC/Companhia das Letras, 1992.

FARAGE, Nádia. As muralhas dos sertões: os povos indígenas no rio Branco e a colonização. Rio de Janeiro: Paz e Terra ; ANPOCS, 1991.

FARAGE, Nádia; SANTILLI, Paulo. Estado de sítio: territórios e identidades no vale do rio Branco. In CUNHA, Manuela Carneiro da (org.). História dos indios no Brasil. São Paulo: Fapesp/SMC/Companhia das Letras, 1992.

FRANK, Erwin H., e Carlos Alberto CIRINO, 2010, "Des-territorialização e reterritorialização dos indígenas de Roraima: uma revisão crítica", em Reinaldo Imbrozio Barbosa e Valdinar F. (orgs.), Roraima: Homem, Ambiente e Ecologia. Boa Vista: FEMACT, 11-33.

LÉVI-STRAUSS, Claude. História de lince; tradução Beatriz Perrone-Moisés. São Paulo: Companhia das Letras, 1993.

. O pensamento selvagem - $10^{\mathrm{a}}$ Edição - Tradução Tânia Pellegrini. Campinas, SP: Papirus, 1989.

LISBOA, João F. K. Escolarização e Intelectuais Indígenas: da formação à emancipação. Revista de estudos e pesquisas sobre as Américas, v.11, p. 2051, 2017.

MELO, Maria Auxiliadora de Souza. Metamorfoses do saber Macuxi/Wapichana: memória e identidade. Dissertação de mestrado em Educação. Faculdade de Educação; Universidade do Amazonas. Manaus: 2000, 171 páginas.

MILANEZ, Felipe. Filhos de Makunaima. Brasil indígena - Fundação Nacional do Índio - FUNAI (especial Raposa Serra do Sol). Ano III, $n^{\circ} 1$, março/abril 2006.

MUMFORD, Lewis. El mito de la máquina: técnica y evolución humana. La Rioja, Spain: Pepitas de calabaza, julio de 2010. 
OLIVEIRA, Alessandro Roberto de. Tempo dos netos. Abundância e escassez nas redes de discursos ecológicos entre os Wapichana na fronteira BrasilGuiana. Tese de doutorado em Antropologia Social, PPGAS, UnB. Brasília, 2012, 340 páginas.

OVERING, Joanna. O mito como história: um problema de tempo, realidade e outras questões. Mana 1(1): 107-140, 1995.

RAMOS, Alcida Rita. Revisitando a etnologia à brasileira. In MARTINS, Carlos Benedito; DUARTE, Luiz Fernando Dias. Horizontes das ciências sociais no Brasil: antropologia. São Paulo: ANPOCS, 2010.

REPETTO, Maxim. Movimentos indígenas e conflitos territoriais no estado de Roraima. Boa Vista: EDUFRR, 2008.

RIBEIRO, Darcy. [1995] O povo brasileiro: a formação e o sentido do Brasil. São Paulo: Companhia das Letras, 2006.

SAHLINS, Marshall. Ilhas de história; tradução Bárbara Sette; revisão técnica Márcia Bandeira de Mello Leite. Rio de Janeiro: Jorge Zahar, 2003.

SANTILLI, Paulo. Pemongon Patá: território Macuxi, rotas de conflito. São Paulo: Editora UNESP, 2001.

SCHWARCZ, Lília Moritz. Questões de fronteira: sobre uma antropologia da história. Novos Estudos, n. 72, p. 119-135, julho 2005.

TASSINARI, Antonella Maria Imperatriz. Escola indígena: novos horizontes teóricos, novas fronteiras de educação. In SILVA, Aracy Lopes da; FERREIRA, Mariana Kawall Leal (Orgs). Antropologia, história e educação:a questão indígena e a escola. São Paulo: Global, 2001.

TAVARES, Flávia. O dia da índia Joênia. O Estado de São Paulo. Edição de domingo, 31 de agosto de 2008 (Caderno Aliás, página J6).

VIEIRA, Jaci Guilherme. Missionários, fazendeiros e índios em Roraima: a disputa pela terra - 1777 a 1980. $2^{\mathrm{a}}$ edição revista e ampliada. Boa Vista: Editora da UFRR, 2014.

WAPICHANA, Joênia Batista de Carvalho. Em defesa dos direitos dos povos indígenas na Raposa Serra do Sol (sustentação oral apresentada no primeiro julgamento no STF, dia 27 de agosto de 2008). In MIRAS, Julia Trujillo et al. (organizadores): Makunaima grita: Terra Indígena Raposa Serra do Sol e os direitos constitucionais no Brasil. Rio de Janeiro: Beco do Azougue, 2009. 